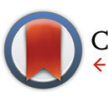

CrossMark \&lick for updates

Cite this: Polym. Chem., 2014, 5 , 7054

Received 2nd July 2014,

Accepted 9th September 2014

DOI: $10.1039 / c 4 p y 00919 c$

www.rsc.org/polymers

\title{
Synthesis of telechelic vinyl/allyl functional siloxane copolymers with structural control $\uparrow$
}

\begin{abstract}
F. B. Madsen, I. Javakhishvili, R. E. Jensen, A. E. Daugaard, S. Hvilsted and A. L. Skov*
Multifunctional siloxane copolymers with terminal vinyl or allyl functional groups are synthesised through the borane-catalysed polycondensation of hydrosilanes and alkoxysilanes. Copolymers of varying molecular weights $\left(\bar{M}_{\mathrm{w}}=13200-70300 \mathrm{~g} \mathrm{~mol}^{-1}\right)$, spatially well-distributed functional groups and high endgroup fidelity are obtained in a facile and robust synthetic scheme involving polycondensation, end-group transformation and different functionalisation reactions such as $\mathrm{Cu}(\mathrm{I})$-mediated azide-alkyne cycloaddition. Pendant alkyl chloride, alkyl azide, bromoisobutyryl, 4-nitrobenzene and 1-ethyl-imidazolium chloride fragments with programmable spatial distributions are incorporated in the copolymer backbones. NMR and FTIR spectroscopy as well as size exclusion chromatography corroborate the efficacy and versatility of this modular approach.
\end{abstract}

\section{Introduction}

The development of functional polymers is attracting increasing interest, due to a growing number of applications within nanotechnology-, sustainability-, biomedical- and energyrelated fields. Functional polymers with specific control over architecture, polarity, functionality, solubility and reactivity are in especially high demand ${ }^{1}$ and controlled functionalisation is often used to change bulk and/or surface properties, in order to expand the application range of a given polymer.

Polysiloxanes, i.e. polymers containing $\mathrm{Si}-\mathrm{O}-\mathrm{Si}$ repeating units, are a group of polymers with significant industrial importance, since especially polysiloxane elastomers are used widely in advanced applications such as adhesives, membranes, implants and dielectric electro active polymers. ${ }^{2-6}$

The synthesis of polysiloxanes is generally accomplished through the nucleophilic substitution of chlorosilanes with water, to form low molecular weight linear silanols and cyclic siloxanes which are further reacted into high molecular weight polymers catalysed by acids or bases. ${ }^{7}$ Ring-opening polymerisation of cyclic siloxanes is very efficient and is extensively used to prepare siloxane homopolymers and random copolymers. ${ }^{8}$ A convenient method for more well-defined copolymers is the dehydrogenative coupling of organohydrosilanes with organohydrosilanols, due to the high selectivity and easy removal of the hydrogen by-product. However, this type of reaction

Technical University of Denmark, Department of Chemical and Biochemical Engineering, Danish Polymer Centre, Building 227, DK-2800 Kgs. Lyngby, Denmark. E-mail: al@kt.dtu.dk; Tel: +45 45252825

$\dagger$ Electronic supplementary information (ESI) available: Numbered structures for

${ }^{13} \mathrm{C}-\mathrm{NMR}$ assignment and ${ }^{1} \mathrm{H}-\mathrm{NMR}$ spectrum of 4. See DOI: $10.1039 / \mathrm{c} 4$ py00919c requires relatively high concentrations $(\geq 0.1 \mathrm{~mol} \%)$ of precious metal catalysts such as platinum, palladium, ruthenium or rhodium. Furthermore, only moderate molecular weight copolymers have been achieved, and undesired silanol selfcondensation can occur and lead to disruption to a perfectly alternating copolymer structure. ${ }^{9-13}$

The Piers-Rubinsztajn reaction, which uses the tris(pentafluorophenyl)borane catalyst, offers an alternative route to structured siloxane copolymers. Piers et al. reported its use as a catalyst for reactions involving organohydrosilanes, ${ }^{14-16}$ while Rubinsztajn and Cella used it afterwards as a catalyst for siloxane homo- and copolymers., ${ }^{8,17,18}$ The Piers-Rubinsztajn reaction therefore refers to a tris(pentafluorophenyl)boranecatalysed reaction between a hydrosilane and an alkoxysilane, forming siloxanes with concomitant loss of an alkane - as seen in Scheme $1 .{ }^{19}$ The reaction is characterised by being exceptionally rapid, mild and efficient, since it can be carried out at ambient temperatures and uses low amounts of borane catalyst.

While functional polysiloxanes with, for example, amino-, chloro- and mercapto-functional groups are commercially available (e.g. from Gelest), they do not contain functional end-groups that allow them to be used in the synthesis of silicone elastomers. It is therefore difficult to obtain from commercially available raw materials elastomers with well distribu-

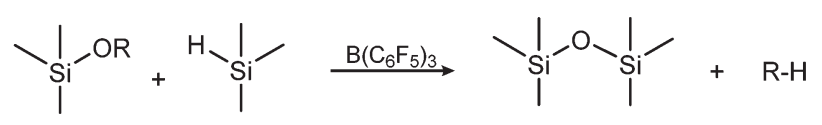

Scheme 1 Condensation reaction between hydrosilanes and alkoxysilanes, forming an inert alkane by-product. 
ted functional groups. Silicone elastomers are frequently prepared by platinum-catalysed hydrosilylation reactions, where vinyl end-groups of polysiloxanes react with hydrosilane groups on siloxane cross-linkers. Functional elastomers can hence be prepared by using one of the components in excess and reacting vinyl- or hydride-functional molecules thereon. This approach, however, compromises network formation, meaning that inferior elastomer properties are thus a consequence. $^{20}$

The aim of this work is to prepare spatially distributed and controlled functional siloxane copolymers through boranecatalysed polycondensation, which offers a rapid and efficient reaction method. The copolymers will contain vinyl or allyl end-groups, which will allow for platinum catalysed crosslinking reactions with hydrosilane cross-linkers. Furthermore, various functional groups along the backbone of the copolymers open up, for example, Williamson ether syntheses or copper-catalysed cycloaddition reactions of azides and alkynes (CuAAC) forming 1,4-disubstituted-1,2,3-triazoles, a so-called "click" reaction. ${ }^{21-24}$ Click reactions, which previously have been used to functionalise polymers in general ${ }^{25-28}$ and polysiloxanes in particular, ${ }^{29-32}$ are particularly efficient in the functionalization of polymers, as they do not form any byproducts and yields are often high.

The prepared copolymers will vary greatly from the siloxane polymers originally prepared by Rubinsztajn and Cella, ${ }^{8,17,18}$ who prepared non-functional alternating aromatic and nonaromatic copolymers, in that the copolymers presented in this study will contain functional end-groups and reactive functional groups, which are spatially well-distributed through the use of dimethylsiloxane pre-polymer spacer units.

Herein we present the synthesis and characterisation of novel functional siloxane copolymers and describe how to tune the obtained molecular weights and the content of the spatially distributed functional units.

\section{Experimental section}

\section{Materials and methods}

Hydride-terminated PDMS, DMS-H11 $\left(\bar{M}_{\mathrm{w}} \sim 1200 \mathrm{~g} \mathrm{~mol}^{-1}\right.$, as determined by $\left.{ }^{1} \mathrm{H}-\mathrm{NMR}\right), 3$-(chloropropyl)methyldimethoxysilane, vinyldimethylsilane and allyldimethylsilane were acquired from Gelest Inc. Hydride-terminated PDMS $\left(\bar{M}_{\mathrm{w}} \sim\right.$ $580 \mathrm{~g} \mathrm{~mol}^{-1}$ as stated by supplier) was purchased from SigmaAldrich. All other chemicals were acquired from Sigma-Aldrich and used as received unless otherwise stated.

FTIR spectroscopy was conducted on PerkinElmer Spectrum One model 2000 Fourier Transform Infrared apparatus equipped with a universal attenuated total reflection accessory on a $\mathrm{ZnSe} /$ diamond composite. Spectra were recorded in the range of $4000-650 \mathrm{~cm}^{-1}$, with $4 \mathrm{~cm}^{-1}$ resolution and 16 scans. ${ }^{1} \mathrm{H}$ - and ${ }^{13} \mathrm{C}-\mathrm{NMR}$ experiments were performed on a Bruker $300 \mathrm{MHz}$ spectrometer in $\mathrm{CDCl}_{3}$, while size-exclusion chromatography (SEC) was performed on a Tosoh EcoSEC HLC-8320GPC instrument equipped with RI and UV detectors and SDV Linear S columns from PSS, Mainz, Germany. Samples were run in toluene at $35^{\circ} \mathrm{C}$ at a rate of $1 \mathrm{~mL} \mathrm{~min}{ }^{-1}$, and molar mass characteristics were calculated using WinGPC Unity 7.4.0 software and linear polydimethylsiloxane (PDMS) standards acquired from PSS, Mainz, Germany.

\section{Syntheses}

All reactions were carried out in a nitrogen atmosphere. Structures for ${ }^{13} \mathrm{C}-\mathrm{NMR}$ assignment can be found in the ESI. $\dagger$

General procedure for Piers-Rubinsztajn polymerisation, $\alpha, \omega$-methoxy-poly((chloropropyl)methylsiloxane-co-dimethylsiloxane) (1). 3-Chloropropylmethyldimethoxysilane $(2.00 \mathrm{~g}$, $10.9 \mathrm{mmol}$ ) was dissolved in dry heptane $(20 \mathrm{~mL})$ in a $250 \mathrm{~mL}$ two-neck round-bottomed flask. Hydride-terminated dimethylsiloxane (Aldrich, $580 \mathrm{~g} \mathrm{~mol}^{-1}$ ) $(6.03 \mathrm{~g}, 10.4 \mathrm{mmol})$ was added and the mixture was stirred for 5 minutes. Tris(pentafluorophenyl)borane (0.6 mL, $0.04 \mathrm{M}, 0.2 \mathrm{~mol} \%)$ in dry toluene $(2 \mathrm{~mL})$ was added and methane gas developed. The mixture was stirred at RT for 1 hour, where after excess dimethoxydimethylsilane (5.26 g, $43.7 \mathrm{mmol}$ ) was added, in order to quench any potentially remaining hydride groups and to ensure that all polymers possessed methoxy end-groups. The reaction mixture was stirred additionally for a couple of hours. The solvent and excess dimethoxydimethylsilane (bp: $82^{\circ} \mathrm{C}$ ) were removed in vacuo at $45^{\circ} \mathrm{C}$ with toluene, to give the product as a clear oil $(7.42 \mathrm{~g}, 96.4 \%)$. IR $\left(\mathrm{cm}^{-1}\right): 2960(\mathrm{C}-\mathrm{H}$ stretch); 1410 ( $\mathrm{Si}-\mathrm{CH}_{2}$ stretch); 1260 ( $\mathrm{Si}-\mathrm{CH}_{3}$ stretch); 1010 (SiO stretch). ${ }^{1} \mathrm{H}$ NMR $\left(\mathrm{CDCl}_{3}, \delta_{\mathrm{H}}, \mathrm{ppm}\right): 0.08-0.09\left(\mathrm{~m}, \mathrm{CH}_{3}-\mathrm{Si}\right)$, $0.63\left(\mathrm{~m},-\mathrm{Si}-\mathrm{CH}_{2}-\mathrm{CH}_{2}-\right), 1.83\left(\mathrm{~m},-\mathrm{CH}_{2}-\mathrm{CH}_{2}-\mathrm{CH}_{2}\right), 3.49(\mathrm{~s}, 6 \mathrm{H}$, $\left.-\mathrm{O}-\mathrm{CH}_{3}\right), 3.50\left(\mathrm{t},{ }^{3} \mathrm{~J}=6.9 \mathrm{~Hz}, \mathrm{Cl}-\mathrm{CH}_{2}-\mathrm{CH}_{2}\right) \cdot{ }^{13} \mathrm{C}-\mathrm{NMR}\left(\mathrm{CDCl}_{3}\right.$, $\left.\delta_{\mathrm{C}}, \mathrm{ppm}\right):-0.51$ to $1.54(\mathrm{e}+\mathrm{f}), 15.06$ (b), 26.78 (c), 47.59 (d), 49.90 (a).

General procedure for end-capping, $\alpha, \omega$-vinyl-poly $(($ chloropropyl)methylsiloxane-co-dimethylsiloxane) (2a-7). Copolymer 1 (1.5 g, 0.073 mmol methoxy end-groups) was dissolved in dry heptane $(20 \mathrm{~mL})$ in a $250 \mathrm{~mL}$ two-neck round-bottomed flask. Vinyldimethylsilane (1.89 g, $21.8 \mathrm{mmol}$ ) was added and the mixture was stirred at RT overnight after which ${ }^{1} \mathrm{H}-\mathrm{NMR}$ was used in order to confirm the removal of methoxy groups and conversion to vinyl groups. Neutral aluminium oxide (5 g) was added to the reaction mixture to remove the tris(pentafluorophenyl)borane catalyst, and the solution was then filtered through $0.45 \mu \mathrm{m}$ PFTE filters. The solvent and excess vinyldimethylsilane reagent were removed in vacuo, to give the product as a clear oil $(1.35 \mathrm{~g}, 90.3 \%)$. IR $\left(\mathrm{cm}^{-1}\right): 2960(\mathrm{C}-\mathrm{H}$ stretch); 1410 ( $\mathrm{Si}-\mathrm{CH}_{2}$ stretch); 1260 ( $\mathrm{Si}-\mathrm{CH}_{3}$ stretch); 1010 ( $\mathrm{Si}-\mathrm{O}$ stretch). ${ }^{1} \mathrm{H}$ NMR $\left(\mathrm{CDCl}_{3}, \delta_{\mathrm{H}}, \mathrm{ppm}\right): 0.08-0.09\left(\mathrm{~m}, \mathrm{CH}_{3}-\mathrm{Si}\right)$, $0.62\left(\mathrm{~m},-\mathrm{Si}-\mathrm{CH}_{2}-\mathrm{CH}_{2}-\right), 1.82\left(\mathrm{~m},-\mathrm{CH}_{2}-\mathrm{CH}_{2}-\mathrm{CH}_{2}-\right), 3.50\left(\mathrm{t},{ }^{3} \mathrm{~J}\right.$ $\left.=6.9 \mathrm{~Hz}, \mathrm{Cl}-\mathrm{CH}_{2}-\mathrm{CH}_{2}\right), 5.74\left(\mathrm{dd}, 2 \mathrm{H},{ }^{2} \mathrm{~J}=4.2 \mathrm{~Hz},{ }^{3} \mathrm{~J}=20 \mathrm{~Hz}\right.$, $\left.\mathrm{CH}=\mathrm{CH}_{2}\right), 5.94\left(\mathrm{dd}, 2 \mathrm{H},{ }^{2} \mathrm{~J}=4.2 \mathrm{~Hz},{ }^{3} \mathrm{~J}=15 \mathrm{~Hz}, \mathrm{CH}=\mathrm{CH}_{2}\right)$, $6.12\left(\mathrm{dd}, 2 \mathrm{H},{ }^{3} \mathrm{~J}=16 \mathrm{~Hz},{ }^{3} J=21 \mathrm{~Hz},-\mathrm{CH}=\mathrm{CH}_{2}\right) .{ }^{13} \mathrm{C}-\mathrm{NMR}$ $\left(\mathrm{CDCl}_{3}, \delta_{\mathrm{C}}, \mathrm{ppm}\right):-0.52$ to $1.53(\mathrm{c}+\mathrm{d}+\mathrm{h}), 15.04$ (e), 26.75 (f), $47.61(\mathrm{~g}), 131.86$ (a), 139.10 (b).

$\alpha, \omega$-Allyl-poly((chloropropyl)methylsiloxane-co-dimethylsiloxane) (2b-1). The polymer was prepared according to the general end-capping procedure using 1 (3 g, 0.14 mmol 
methoxy end-groups) and allyldimethylsilane $(4.38 \mathrm{~g}$, $43.7 \mathrm{mmol})$ to give a clear oil $(2.85 \mathrm{~g}, 95.1 \%)$ IR $\left(\mathrm{cm}^{-1}\right): 2960$ (C-H stretch); 1630 (C=C stretch); $1410\left(\mathrm{Si}-\mathrm{CH}_{2}\right.$ stretch); 1260 $\left(\mathrm{Si}-\mathrm{CH}_{3}\right.$ stretch); 1010 ( $\mathrm{Si}-\mathrm{O}$ stretch). ${ }^{1} \mathrm{H} \mathrm{NMR}\left(\mathrm{CDCl}_{3}, \delta_{\mathrm{H}}\right.$, ppm): -0.05 to 0.09 (m, $\left.\mathrm{CH}_{3}-\mathrm{Si}\right), 0.62\left(\mathrm{~m},-\mathrm{Si}-\mathrm{CH}_{2}-\mathrm{CH}_{2}-\right), 1.50$ $\left(\mathrm{d}, 4 \mathrm{H},{ }^{3} \mathrm{~J}=8.1 \mathrm{~Hz}, \mathrm{CH}_{2}-\mathrm{CH}=\mathrm{CH}_{2}\right), 1.82\left(\mathrm{~m},-\mathrm{CH}_{2}-\mathrm{CH}_{2}-\mathrm{CH}_{2}-\right.$ ), $3.50\left(\mathrm{t},{ }^{3} \mathrm{~J}=6.9 \mathrm{~Hz}, \mathrm{Cl}-\mathrm{CH}_{2}-\mathrm{CH}_{2}\right), 4.83\left(\mathrm{~m}, 4 \mathrm{H}, \mathrm{CH}=\mathrm{CH}_{2}\right), 5.77$ $\left(\mathrm{m}, 2 \mathrm{H}, \mathrm{CH}=\mathrm{CH}_{2}\right) .{ }^{13} \mathrm{C}-\mathrm{NMR}\left(\mathrm{CDCl}_{3}, \delta_{\mathrm{C}}, \mathrm{ppm}\right):-0.53$ to 1.54 (d + e + i), 15.04 (f), 23.41 (c), 26.75 (g), 47.61 (h), 112.53 (a), $135.30(\mathrm{~b})$.

$\alpha, \omega$-Allyl-poly((azidopropyl)methylsiloxane-co-dimethylsiloxane) (3). Following a procedure adapted from Rambarran et $a .^{33}$ copolymer $\mathbf{2 b - 1}(0.75 \mathrm{~g}, \sim 1.02 \mathrm{mmol}$ (chloropropyl) methylsiloxane units), $\mathrm{NaN}_{3}(0.35 \mathrm{~g}, 5.4 \mathrm{mmol})$ and tetrabutylammonium azide $(0.03 \mathrm{~g}, 0.11 \mathrm{mmol})$ were dissolved in dry THF $(10 \mathrm{~mL})$ in a $100 \mathrm{~mL}$ round-bottomed flask. The reaction mixture was stirred under reflux for 48 hours. THF was removed in vacuo and the reaction mixture was re-dissolved in heptane $(20 \mathrm{~mL})$, washed with water $(3 \times 20 \mathrm{~mL})$ and brine $(1 \times$ $20 \mathrm{~mL}$ ), dried with $\mathrm{MgSO}_{4}$ and then filtered and concentrated in vacuo to afford a transparent, viscous liquid $(0.67 \mathrm{~g}, 89.5 \%)$. IR $\left(\mathrm{cm}^{-1}\right)$ : 2960 (C-H stretch); $2095\left(-\mathrm{N}_{3}\right.$ stretch); $1630(\mathrm{C}=\mathrm{C}$ stretch); 1410 ( $\mathrm{Si}-\mathrm{CH}_{2}$ stretch); 1260 ( $\mathrm{Si}-\mathrm{CH}_{3}$ stretch); 1010 (SiO stretch). ${ }^{1} \mathrm{H} \mathrm{NMR}\left(\mathrm{CDCl}_{3}, \delta_{\mathrm{H}}, \mathrm{ppm}\right):-0.05$ to 0.09 (m, $\mathrm{CH}_{3}-$ $\mathrm{Si}), 0.58\left(\mathrm{~m},-\mathrm{Si}-\mathrm{CH}_{2}-\mathrm{CH}_{2}-\right), 1.50\left(\mathrm{~d}, 4 \mathrm{H},{ }^{3} \mathrm{~J}=8.1 \mathrm{~Hz}, \mathrm{CH}_{2}-\right.$ $\left.\mathrm{CH}=\mathrm{CH}_{2}\right), 1.65\left(\mathrm{~m},-\mathrm{CH}_{2}-\mathrm{CH}_{2}-\mathrm{CH}_{2}-\right), 3.23\left(\mathrm{t},{ }^{3} \mathrm{~J}=7.1 \mathrm{~Hz}, \mathrm{~N}_{3}-\right.$ $\left.\mathrm{CH}_{2}-\mathrm{CH}_{2}\right), 4.83\left(\mathrm{~m}, 4 \mathrm{H}, \mathrm{CH}=\mathrm{CH}_{2}\right), 5.77\left(\mathrm{~m}, 2 \mathrm{H}, \mathrm{CH}=\mathrm{CH}_{2}\right)$. ${ }^{13} \mathrm{C}-\mathrm{NMR}\left(\mathrm{CDCl}_{3}, \delta_{\mathrm{C}}, \mathrm{ppm}\right):-0.55$ to $1.03(\mathrm{~d}+\mathrm{e}+\mathrm{i}), 14.50$ (f), 22.77 (g), 23.40 (c), 54.14 (h), 112.51 (a), 135.32 (b).

General procedure for CuAAC click reactions, synthesis of $\alpha, \omega$-allyl-poly((2-bromo-2-methylpropanoate)-1H-1,2,3-triazolepropyl)methylsiloxane-co-dimethylsiloxane) (4). $3 \quad(0.2 \quad \mathrm{~g}$, $\sim 0.27 \mathrm{mmol}$ (azidopropyl)methylsiloxane units) and propargyl2-bromoisobutyrate $(0.06 \mathrm{~g}, 0.28 \mathrm{mmol})$ were dissolved in dry THF $(3.5 \mathrm{~mL})$ in a $25 \mathrm{~mL}$ two-neck round-bottomed flask. CuI (0.006 g, $0.03 \mathrm{mmol}$ ) was subsequently added and $\mathrm{Et}_{3} \mathrm{~N}$ $(0.04 \mathrm{~g}, 0.43 \mathrm{mmol})$ was added drop-wise. The reaction was carried out at RT for 17 hours at which point FTIR confirmed the disappearance of the azide band at $2095 \mathrm{~cm}^{-1}$. THF was evaporated and the reaction mixture was precipitated into cold methanol. The solvent was then decanted and the product was dried in vacuo, providing a dark-green viscous oil (0.18 g, $74.0 \%$ - after precipitation). IR $\left(\mathrm{cm}^{-1}\right): 2960$ (C-H stretch); $1740(\mathrm{C}=\mathrm{O}$ stretch$) ; 1630(\mathrm{C}=\mathrm{C}$ stretch$) ; 1465$ (C-H bend); 1370 (C-H bend); 1410 ( $\mathrm{Si}-\mathrm{CH}_{2}$ stretch); 1260 ( $\mathrm{Si}-\mathrm{CH}_{3}$ stretch); 1155 (C-O stretch); 1010 (Si-O stretch). ${ }^{1} \mathrm{H} \mathrm{NMR}\left(\mathrm{CDCl}_{3}, \delta_{\mathrm{H}}\right.$, ppm): -0.06 to 0.13 (m, $\left.\mathrm{CH}_{3}-\mathrm{Si}\right), 0.58$ (m, $\left.-\mathrm{Si}-\mathrm{CH}_{2}-\mathrm{CH}_{2}-\right), 1.54$ (d, $\left.4 \mathrm{H},{ }^{3} \mathrm{~J}=7.8 \mathrm{~Hz}, \mathrm{CH}_{2}-\mathrm{CH}=\mathrm{CH}_{2}\right), 1.82\left(\mathrm{~m},-\mathrm{CH}_{2}-\mathrm{CH}_{2}-\mathrm{CH}_{2}-\right.$ ), $1.91\left(\mathrm{~s}, \mathrm{Br}-\mathrm{C}\left(\mathrm{CH}_{3}\right)_{2}\right), 4.33\left(\mathrm{t},{ }^{3} \mathrm{~J}=7.2 \mathrm{~Hz}, \mathrm{~N}-\mathrm{CH}_{2}-\mathrm{CH}_{2}\right), 4.84(\mathrm{~m}$, $\left.4 \mathrm{H}, \mathrm{CH}=\mathrm{CH}_{2}\right), 5.33(\mathrm{~s}, \mathrm{C}-\mathrm{CH}-\mathrm{O}), 5.76\left(\mathrm{~m}, 2 \mathrm{H}, \mathrm{CH}=\mathrm{CH}_{2}\right), 7.61$ $(\mathrm{s},-\mathrm{C}=\mathrm{CH}-\mathrm{N}) .{ }^{13} \mathrm{C}-\mathrm{NMR}\left(\mathrm{CDCl}_{3}, \delta_{\mathrm{C}}, \mathrm{ppm}\right):-0.57$ to $1.03(\mathrm{~d}+\mathrm{e}$ $+\mathrm{q}), 14.24$ (f), 24.33 (g), 30.62 (p), 52.97 (h), 55.53 (o), 59.22 (k), 123.47 (i), 142.25 (j), 171.46 (l) (a, b and c not visible).

Synthesis of $\alpha, \omega$-allyl-poly((4-(4-nitrophenyl)-1H-1,2,3-triazolepropyl)methylsiloxane-co-dimethylsiloxane) (5). The polymer was prepared according to the general click reaction procedure using 3 (0.1 g, 0.14 mmol (azidopropyl)methylsiloxane units), 1-ethynyl-4-nitrobenzene $(0.05 \mathrm{~g}, 0.31 \mathrm{mmol})$, CuI $(0.005 \mathrm{~g}$, $0.02 \mathrm{mmol})$ and $\mathrm{Et}_{3} \mathrm{~N}(0.03 \mathrm{~g}, 0.28 \mathrm{mmol})$ for 24 hours at $45{ }^{\circ} \mathrm{C}$ to give a red viscous oil ( $0.08 \mathrm{~g}, 69.3 \%$ - after precipitation). IR $\left(\mathrm{cm}^{-1}\right)$ : 2960 (C-H stretch); 1605 (aromatic $\mathrm{C}=\mathrm{C}$ stretch); 1520 $\left(\mathrm{N}=\mathrm{O}\right.$ asymmetric stretch); $1410\left(\mathrm{Si}-\mathrm{CH}_{2}\right.$ stretch $) ; 1340(\mathrm{~N}=\mathrm{O}$ symmetric stretch); 1260 ( $\mathrm{Si}-\mathrm{CH}_{3}$ stretch); 1010 ( $\mathrm{Si}-\mathrm{O}$ stretch). ${ }^{1} \mathrm{H}$ NMR (CDCl3, $\left.\delta_{\mathrm{H}}, \mathrm{ppm}\right):-0.45$ to $0.13\left(\mathrm{~m}, \mathrm{CH}_{3}-\mathrm{Si}\right), 0.55(\mathrm{~m}$, $-\mathrm{Si}-\mathrm{CH}_{2}-\mathrm{CH}_{2}-$ ), 1.57 (d, $4 \mathrm{H},{ }^{3} \mathrm{~J}=8.1 \mathrm{~Hz}, \mathrm{CH}_{2}-\mathrm{CH}=\mathrm{CH}_{2}$ ), 2.02 $\left(\mathrm{m},-\mathrm{CH}_{2}-\mathrm{CH}_{2}-\mathrm{CH}_{2}-\right), 4.41\left(\mathrm{t},{ }^{3} \mathrm{~J}=7.2 \mathrm{~Hz}, \mathrm{~N}-\mathrm{CH}_{2}-\mathrm{CH}_{2}\right), 4.83$ $\left(\mathrm{m}, 4 \mathrm{H}, \mathrm{CH}=\mathrm{CH}_{2}\right), 5.77\left(\mathrm{~m}, 2 \mathrm{H}, \mathrm{CH}=\mathrm{CH}_{2}\right), 7.90(\mathrm{~s},-\mathrm{C}=\mathrm{CH}-$ $\mathrm{N}), 7.99(\mathrm{~m}, \mathrm{Ar}-H), 8.27\left(\mathrm{~m}, \mathrm{NO}_{2}-\mathrm{Ar}-H\right) .{ }^{13} \mathrm{C}-\mathrm{NMR}\left(\mathrm{CDCl}_{3}, \delta_{\mathrm{C}}\right.$, ppm): -0.55 to $1.03(\mathrm{~d}+\mathrm{e}+\mathrm{q}), 14.23(\mathrm{f}), 24.39(\mathrm{~g}), 53.09(\mathrm{~h})$, 120.68 (i), 124.29 (o), 126.05 (l), 137.04 (k), 145.45 (p), 147.26 (j) (a, b and c not visible).

Synthesis of $\alpha, \omega$-vinyl-poly $((1-$-ethyl-1 $\mathrm{H}$-imidazol-3-ium chloride)-1H-1,2,3-triazolepropyl)methylsiloxane-co-dimethylsiloxane) (6). $2 \mathrm{a}-8 \quad(14.0 \quad \mathrm{~g}, \quad \sim 19.1 \quad \mathrm{mmol}$ (chloropropyl) methylsiloxane units) and 1-ethylimidazole $(9.19 \mathrm{~g}$, $95.6 \mathrm{mmol}$ ) were mixed in a $250 \mathrm{~mL}$ two-neck round-bottomed flask. The reaction was carried out at $95{ }^{\circ} \mathrm{C}$ for 48 hours under reflux. The product was washed four times with toluene to remove excess 1-ethylimidazole and then dried in vacuo to give the product as an orange-brown oil $(7.3 \mathrm{~g}, 46.0 \%)$. IR $\left(\mathrm{cm}^{-1}\right)$ : $3085(\mathrm{C}=\mathrm{C}$ stretch); $2965(\mathrm{C}-\mathrm{H}$ stretch $) ; 1630(\mathrm{C}=\mathrm{N}, \mathrm{C}=\mathrm{C}$ stretch); $1565(\mathrm{C}=\mathrm{N}$ ring stretch); 1455 (C-H bend); 1405 ( $\mathrm{Si}-$ $\mathrm{CH}_{2}$ stretch); 1260 ( $\mathrm{Si}-\mathrm{CH}_{3}$ stretch); 1010 (Si-O stretch). ${ }^{1} \mathrm{H}$ NMR $\left(\mathrm{CDCl}_{3}, \delta_{\mathrm{H}}, \mathrm{ppm}\right)$ : 0.073-0.16 (m, $\left.\mathrm{CH}_{3}-\mathrm{Si}\right), 0.54$ (m, -Si$\left.\mathrm{CH}_{2}-\mathrm{CH}_{2}-\right), 1.60\left(\mathrm{~m}, \mathrm{CH}_{3}-\mathrm{CH}_{2}-\mathrm{N}-\right), 1.94\left(\mathrm{~m},-\mathrm{CH}_{2}-\mathrm{CH}_{2}-\mathrm{CH}_{2}-\right)$, $4.35\left(\mathrm{~m}, \mathrm{CH}_{3}-\mathrm{CH}_{2}-\mathrm{N}-\right), 4.43\left(\mathrm{~m},-\mathrm{N}^{+}-\mathrm{CH}_{2}-\mathrm{CH}_{2}-\mathrm{CH}_{2}-\right), 5.73$ $\left(\mathrm{dd}, 2 \mathrm{H},{ }^{2} \mathrm{~J}=4.2 \mathrm{~Hz},{ }^{3} \mathrm{~J}=20 \mathrm{~Hz}, \mathrm{CH}=\mathrm{CH}_{2}\right), 5.94\left(\mathrm{dd}, 2 \mathrm{H},{ }^{2} \mathrm{~J}=\right.$ $\left.4.1 \mathrm{~Hz},{ }^{3} \mathrm{~J}=15 \mathrm{~Hz}, \mathrm{CH}=\mathrm{CH}_{2}\right), 6.13\left(\mathrm{dd}, 2 \mathrm{H},{ }^{3} \mathrm{~J}=15 \mathrm{~Hz},{ }^{3} \mathrm{~J}=20\right.$ $\mathrm{Hz},-\mathrm{CH}=\mathrm{CH}_{2}$ ), $7.42\left(\mathrm{~d},{ }^{3} \mathrm{~J}=1.5 \mathrm{~Hz}, \mathrm{~N}^{+}-\mathrm{CH}=\mathrm{CH}-\right), 7.60$ (d, ${ }^{3} \mathrm{~J}=$ $\left.1.5 \mathrm{~Hz}, \mathrm{~N}^{+}-\mathrm{CH}=\mathrm{CH}-\right), 10.9\left(\mathrm{~s},-\mathrm{N}-\mathrm{CH}=\mathrm{N}^{+}-\right) .{ }^{13} \mathrm{C}-\mathrm{NMR}\left(\mathrm{CDCl}_{3}\right.$, $\left.\delta_{\mathrm{C}}, \mathrm{ppm}\right):-0.66$ to $1.09(\mathrm{c}+\mathrm{d}+\mathrm{m}), 13.60(\mathrm{e}), 15.53(\mathrm{k}), 24.24$ (f), 45.10 (j), 52.07 (g), 121.34 (i), 122.15 (h), 136.54 (l) (a and b not visible).

\section{Results and discussion}

Siloxane copolymers with spatially well-distributed functional groups were prepared as illustrated in Scheme 2. Synthesis was accomplished through the tris(pentafluorophenyl)borane-catalysed Piers-Rubinsztajn reaction of 3-chloropropylmethyldimethoxysilane and hydride-terminated dimethylsiloxane pre-polymers to form methoxy-terminated copolymers 1 . The borane-catalysed polycondensation of hydrosilanes and methoxysilanes to form 1 involves cleaving $\mathrm{C}-\mathrm{O}$ and $\mathrm{Si}-\mathrm{H}$ bonds while forming $\mathrm{Si}-\mathrm{O}$ and $\mathrm{C}-\mathrm{H}$ bonds in an exothermic reaction $\left(\Delta H \approx-250 \mathrm{KJ} \mathrm{mol}^{-1}\right) .^{8}$ The reaction is performed at room temperature using low levels of $\mathrm{B}\left(\mathrm{C}_{6} \mathrm{~F}_{5}\right)_{3}$ catalyst $(<0.5 \mathrm{~mol} \%)$. At higher catalyst concentrations ( 1-5 mol\%), hydrosilylation reactions may compete with the Piers-Rubinsztajn polycondensation reaction. ${ }^{34,35}$ The reaction is almost instantaneous and is completed within a few minutes, but it was left to stir 


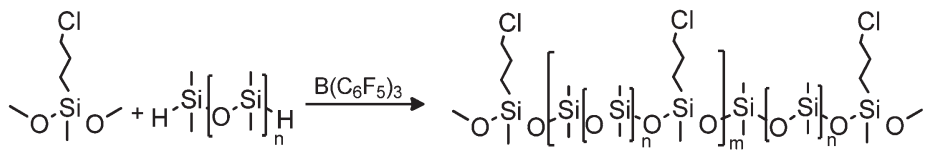

1

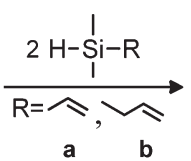

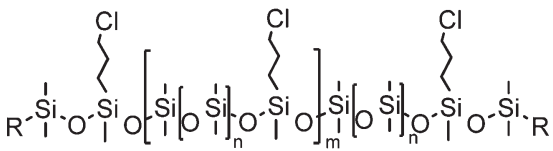

2

Scheme 2 Synthetic route for telechelic vinyl/allyl siloxane copolymers via borane catalysed polycondensation.

for 1 hour, in order to ensure the full conversion of reagents. Furthermore, high yields were obtained $(>95 \%)$. At this point ${ }^{1} \mathrm{H}$-NMR and FTIR spectroscopy were used to confirm the completeness of the reaction through assessing the disappearance of the hydride-groups on the hydride-terminated pre-polymers. In ${ }^{1} \mathrm{H}-\mathrm{NMR}$, resonance at $\delta_{\mathrm{H}}=4.7 \mathrm{ppm}$ disappeared, which was also corroborated by FTIR, where the distinctive stretch at $2125 \mathrm{~cm}^{-1}$ was no longer present. In order to ensure at this stage that all polymers contained methoxy end-groups, significant amount of excess dimethoxydimethylsilane was added to the reaction mixture so that any remaining hydride groups would react. The excess dimethoxydimethylsilane was easily removed in vacuo.

The prepared copolymers were characterised by SEC, and molar mass characteristics were calculated from linear polydimethylsiloxane standards. The results are summarised in Table 1. Two dimethylsiloxane pre-polymers of different molecular weights were used, in order to create copolymers with varying mol\% of the (chloropropyl)methylsiloxane unit and with different spacer lengths between the functional groups. The molecular weights of the final copolymers were varied furthermore by changing the stoichiometry between the hydrosilane pre-polymers and the methoxysilane compound. According to standard polycondensation theory, the highest molecular weight would be obtained when using stoichiometries closest to unity. ${ }^{36}$ This is not the case in these experiments, solely due to rough estimates of exact pre-polymer molecular weights, in which case the exact stoichiometry cannot be calculated. In the case of the pre-polymer of $\bar{M}_{\mathrm{w}} \sim$ $1200 \mathrm{~g} \mathrm{~mol}^{-1}$ the highest molecular weight is obtained when using a stoichiometry of hydrosilane-methoxysilane of 0.95/1, with a molecular weight of $\bar{M}_{\mathrm{w}}=70300 \mathrm{~g} \mathrm{~mol}^{-1}$. For the prepolymer of $\bar{M}_{\mathrm{w}} \sim 580 \mathrm{~g} \mathrm{~mol}^{-1}$ the highest molecular weight was obtained using the stoichiometry of hydrosilane-methoxysilane of $1 / 0.95$, where $\bar{M}_{\mathrm{w}}=56700 \mathrm{~g} \mathrm{~mol}^{-1}$ was attained.

In order to test the reproducibility of the borane-catalysed polycondensations a reaction with the pre-polymer of $\bar{M}_{\mathrm{w}} \sim$ $1200 \mathrm{~g} \mathrm{~mol}^{-1}$ was repeated. As seen in Table 1, entries 2a-2 and $2 \mathrm{a}-3$ were prepared using similar reaction conditions, and SEC provided comparable results for both experiments. This shows that the polycondensation reaction is quite robust when using similar reaction conditions.

The aim of this study was to create functional copolymers with molecular weights suitable for silicone elastomer synthesis. The best elastomer properties are usually obtained when using polymers with molecular weights of $\bar{M}_{\mathrm{w}} \sim$ 20000-30000 $\mathrm{g} \mathrm{mol}^{-1} .{ }^{37}$ Molecular weights in this range were obtained for copolymer 2a-4 with a stoichiometric ratio of hydrosilane-methoxysilane of 1/0.9 using the pre-polymer of $\bar{M}_{\mathrm{w}} \sim 1200 \mathrm{~g} \mathrm{~mol}^{-1}$, where a molecular weight of $\bar{M}_{\mathrm{w}}=25900 \mathrm{~g}$ $\mathrm{mol}^{-1}$ was reached, and for $\mathbf{2 a - 7}, \mathbf{2 a - 8}$ and $\mathbf{2 b - 1}$ with stoichiometries of hydrosilane-methoxysilane of $0.95 / 1$ and $0.975 / 1$, respectively, using the pre-polymer of $\bar{M}_{\mathrm{w}} \sim 580 \mathrm{~g} \mathrm{~mol}^{-1}$, where molecular weights of $\bar{M}_{\mathrm{w}}=20600 \mathrm{~g} \mathrm{~mol}{ }^{-1}, \bar{M}_{\mathrm{w}}=22500 \mathrm{~g}$ $\mathrm{mol}^{-1}$ and $\bar{M}_{\mathrm{w}}=22100 \mathrm{~g} \mathrm{~mol}^{-1}$ were achieved. Copolymers prepared with the $\bar{M}_{\mathrm{w}} \sim 1200 \mathrm{~g} \mathrm{~mol}^{-1}$ pre-polymer display polydispersity indexes $\left(\bar{M}_{\mathrm{w}} / \bar{M}_{\mathrm{n}}\right)$ from 2.20 to 3.80 , whereas copolymers prepared with the lower molecular weight pre-polymer of $\bar{M}_{\mathrm{w}} \sim 580 \mathrm{~g} \mathrm{~mol}^{-1}$ display $\bar{M}_{\mathrm{w}} / \bar{M}_{\mathrm{n}}$ in the range of 2.84 to 3.62 .

Table 1 SEC results for prepared functional siloxane copolymers with varying pendant groups as well as varying end-groups

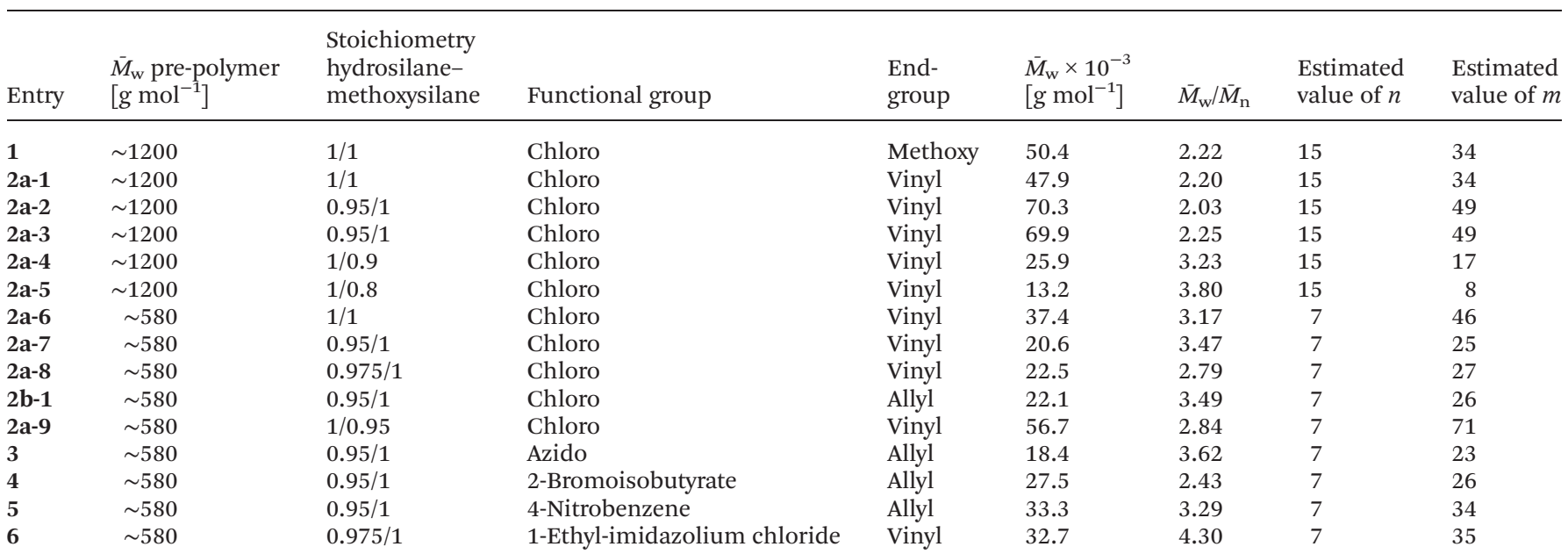




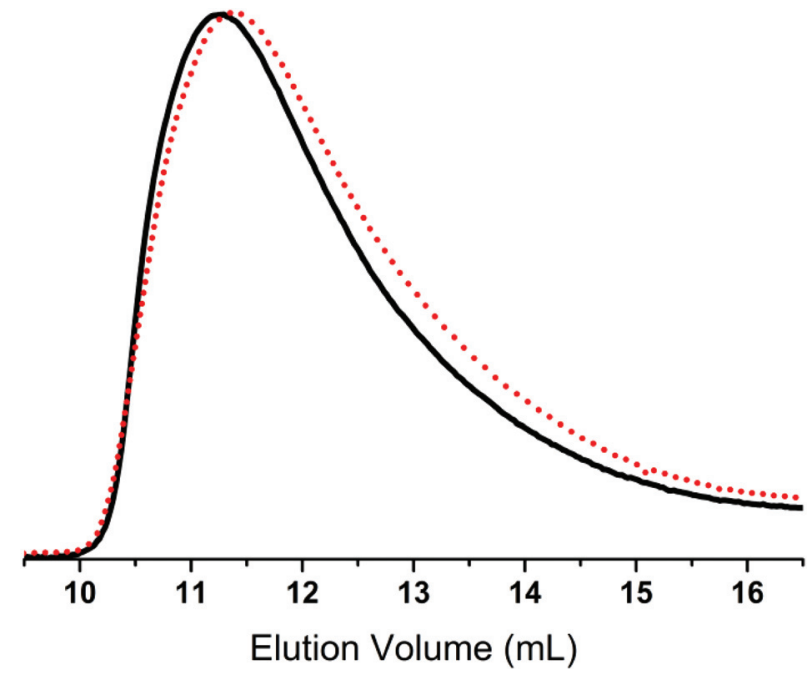

Fig. 1 An overlay of the RI SEC traces of methoxy end-functional copolymer 1 (black, --) and vinyl end-functional copolymer 2a-1 (red, ...).

End-functionalisation of $\mathbf{1}$ with vinyl- or allyldimethylsilane produced copolymers $\mathbf{2 a}$ and $\mathbf{2 b}$, as seen in Scheme 2. These end-groups were chosen because they allow prepared copolymers to be used in the synthesis of silicone elastomers in platinum-catalysed hydrosilylation reactions. It is also possible to create copolymers with other end-groups, as long as the groups are compatible with the borane-catalysed reaction. Such end-groups, for example, could be, but are not limited to, silanes with aliphatics such as trimethyl-groups, aromatics and halogen-containing compounds. ${ }^{38}$ The prepared telechelic vinyl/allyl copolymers were characterised by FTIR spectroscopy, ${ }^{1} \mathrm{H}$ - and ${ }^{13} \mathrm{C}-\mathrm{NMR}$ spectroscopy and SEC. The end-group conversion was investigated by NMR using low molecular weight copolymers, i.e. 2-a5, 2a-7 and 2b-1. In this way it was ensured that the end-groups were clearly visible in the recorded spectra. For the telechelic vinyl copolymers (2a) ${ }^{1} \mathrm{H}$ - and ${ }^{13} \mathrm{C}$-NMR confirmed the reaction through the disappearance of the $\mathrm{O}-\mathrm{CH}_{3}$ protons and a carbon atom at $\delta_{\mathrm{H}}=3.49 \mathrm{ppm}$ and $\delta_{\mathrm{C}}$ $=49.9 \mathrm{ppm}$, respectively. The presence of $-\mathrm{CH}=\mathrm{CH}_{2}$ protons as three distinctive doublets of doublets at $\delta_{\mathrm{H}}=5.74-6.12 \mathrm{ppm}$ in the ${ }^{1} \mathrm{H}$-NMR spectrum of 2 a points to the successful formation of vinyl end-groups. Furthermore, the presence of
$-\mathrm{CH}=\mathrm{CH}_{2}$ groups can be detected in the ${ }^{13} \mathrm{C}-\mathrm{NMR}$ spectra of 2a with resonances at $\delta_{\mathrm{C}}=131.86$ and $139.10 \mathrm{ppm}$. For telechelic allyl copolymers $(\mathbf{2 b})$ the reactions could be followed similarly by ${ }^{1} \mathrm{H}$ - and ${ }^{13} \mathrm{C}-\mathrm{NMR}$ through the disappearance of the $\mathrm{O}-\mathrm{CH}_{3}$ protons and a carbon atom at $\delta_{\mathrm{H}}=3.49 \mathrm{ppm}$ and $\delta_{\mathrm{C}}=$ $49.9 \mathrm{ppm}$, respectively. The allyl-groups were detected by ${ }^{1} \mathrm{H}-\mathrm{NMR}$ as resonances at $\delta_{\mathrm{H}}=1.5 \mathrm{ppm}\left(-\mathrm{CH}_{2}-\mathrm{CH}=\mathrm{CH}_{2}\right), \delta_{\mathrm{H}}=$ 4.86-4.92 ppm $\left(-\mathrm{CH}=\mathrm{CH}_{2}\right)$ and $\delta_{\mathrm{H}}=5.79 \mathrm{ppm}\left(-\mathrm{CH}=\mathrm{CH}_{2}\right)$ and by ${ }^{13} \mathrm{C}-\mathrm{NMR}$ as resonances at $\delta_{\mathrm{C}}=26.4 \mathrm{ppm}\left(\mathrm{CH}_{2}-\right.$ $\left.\mathrm{CH}=\mathrm{CH}_{2}\right), \quad \delta_{\mathrm{C}}=113.7 \mathrm{ppm}\left(-\mathrm{CH}=\mathrm{CH}_{2}\right)$ and $133.8 \mathrm{ppm}$ $\left(-\mathrm{CH}=\mathrm{CH}_{2}\right)$.

Converting the methoxy end-groups to vinyl/allyl endgroups did not alter the molecular weight of the copolymers, as illustrated in the SEC traces presented in Fig. 1. This also indicates that no unintended hydrosilylation reactions between the end-groups and vinyl- or allyldimethylsilane occur.

The synthesised chloro-functional copolymers were converted to azido-functional (3) through nucleophilic substitution in THF, using tetrabutylammonium azide as a phasetransfer catalyst as seen in Scheme 3. Entry $\mathbf{2 b - 1}$ was selected for this purpose, as the obtained molecular weight of $\bar{M}_{\mathrm{w}}=$ $22100 \mathrm{~g} \mathrm{~mol}^{-1}$ lies within the desired range for use in elastomer synthesis. The copolymer was successfully converted from chloro- to azido-functional, and this reaction was followed by FTIR through the appearance of the distinctive $-\mathrm{N}_{3}$ band at $2095 \mathrm{~cm}^{-1}$. Furthermore, ${ }^{1} \mathrm{H}$ - and ${ }^{13} \mathrm{C}-\mathrm{NMR}$ corroborated this through a shift in the resonance signals of $\mathrm{CH}_{2}-\mathrm{Cl}\left(\delta_{\mathrm{H}}=\right.$ $\left.3.50 \mathrm{ppm}, \delta_{\mathrm{C}}=47.6 \mathrm{ppm}\right)$ to $\mathrm{CH}_{2}-\mathrm{N}_{3}\left(\delta_{\mathrm{H}}=3.23 \mathrm{ppm}, \delta_{\mathrm{C}}=\right.$ $54.1 \mathrm{ppm})$. The prepared azido-functional copolymer was characterised by SEC, the results for which are shown in Fig. 2 . It is evident that the molecular weight after the azide-substitution reaction is lower than for the corresponding chlorofunctional copolymer, which could indicate that degradation has taken place. However, upon examination of the SEC overlays seen in Fig. 2, it is clear that no degradation has taken place, as both chromatograms are broad yet monomodal, with no lower molecular weight fragments appearing at higher elution volumes.

The lower obtained $\bar{M}_{\mathrm{W}}$ for the azido-functional copolymer must be ascribed to tailing and a shift in the baseline due to enhanced interactions of the latter with the SEC columns.

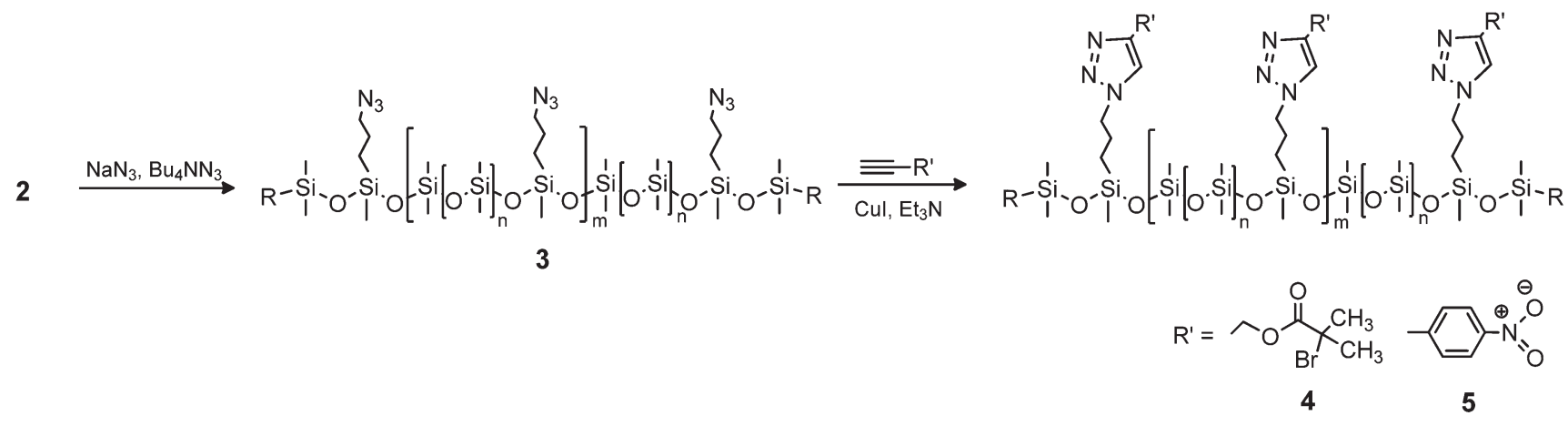

Scheme 3 Synthetic route to azido- and CUAAC-functionalised copolymers. 


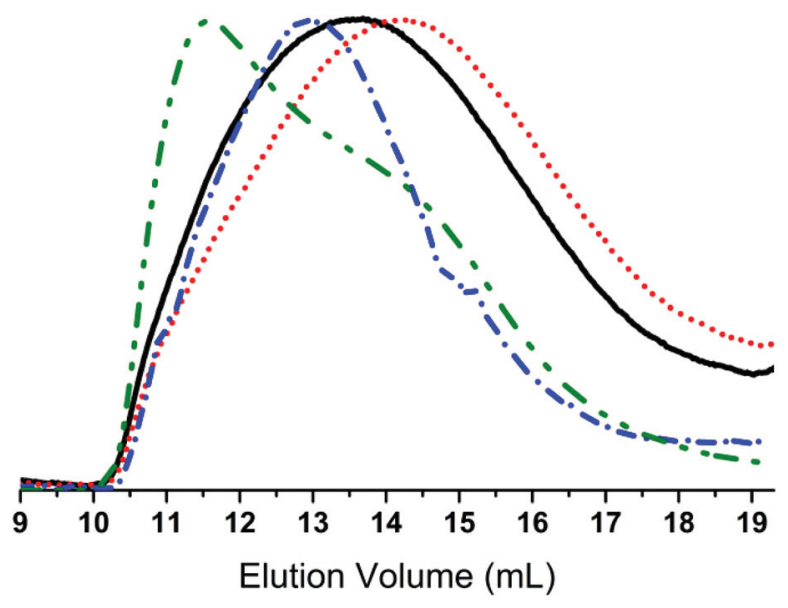

Fig. 2 An overlay of the RI SEC traces of chloro-functional copolymer 2b-1 (black, --), azido-functional copolymer 3 (red, ... •), 2-bromoisobutyrate-functional copolymer 4 (blue, $-\cdot)$ and nitrobenzene-functional copolymer 5 (green, - • •).

Functional dimethylsiloxane copolymers were created through a reaction with alkyne-functional molecules using CuAAC. Two different alkyne-containing molecules were chosen, in order to illustrate the versatility of the reaction. An aliphatic ATRP initiator and an alkyne-functional nitrobenzene were utilised as seen in Scheme 3. The ATRP initiator can be used to create polysiloxanes with different polymer side chains, whereas the aromatic compound 4-nitrobenzene can be used to increase dielectric permittivity in dielectric silicone elastomers. ${ }^{32}$ Click-functionalised copolymers were prepared under similar reaction conditions by means of a CuI-Et ${ }_{3} \mathrm{~N}$ catalytic system. The reaction products were characterised by FTIR spectroscopy, ${ }^{1} \mathrm{H}$ - and ${ }^{13} \mathrm{C}$-NMR spectroscopy and SEC. FTIR was used to confirm the completion of the click reaction through the disappearances of the alkyne and azide bands at $\sim 3300 \mathrm{~cm}^{-1}$ and $\sim 2095 \mathrm{~cm}^{-1}$, respectively. For the reaction with the ATRP initiator (4), which produced a green-brown polymer, a distinct ester $\mathrm{C}=\mathrm{O}$ band at $1740 \mathrm{~cm}^{-1}$ confirmed the presence of the 2-bromoisobutyrate group. In 5 the presence of 4-nitrobenzene was indicated by the red colour of the obtained polymer confirmed by bands at $\sim 1605 \mathrm{~cm}^{-1}$ for the aromatic $\mathrm{C}=\mathrm{C}$ bonds and at $\sim 1520 \mathrm{~cm}^{-1}$ and $\sim 1340 \mathrm{~cm}^{-1}$ for the $\mathrm{N}=\mathrm{O}$ bonds. FTIR spectra of $\mathbf{3}, \mathbf{4}$ and $\mathbf{5}$ can be seen in Fig. 3. The formation of the click products was furthermore confirmed by the presence of the triazole protons in ${ }^{1} \mathrm{H}-\mathrm{NMR}$, which appear at $\delta_{\mathrm{H}}=7.61 \mathrm{ppm}$ and $\delta_{\mathrm{H}}=7.90 \mathrm{ppm}$ for $\mathbf{4}$ and $\mathbf{5}$, respectively. An assigned representative ${ }^{1} \mathrm{H}-\mathrm{NMR}$ spectrum of $\mathbf{4}$ can be found in the ESI. $\dagger$

The SEC results for click-products 4 and $\mathbf{5}$ can be seen in Table 1 and Fig. 2. For both click-products higher molecular weights are obtained, and a slight shift towards higher molecular weight regions can be seen in the SEC traces, pointing to the successful attachment of functional groups onto the copolymers. Furthermore, SEC showed that 5 had a strong UV signal, unlike the starting materials $\mathbf{2 b - 1}$ and $\mathbf{3}$, which proves the attachment of the 4-nitrobenzene chromophore.

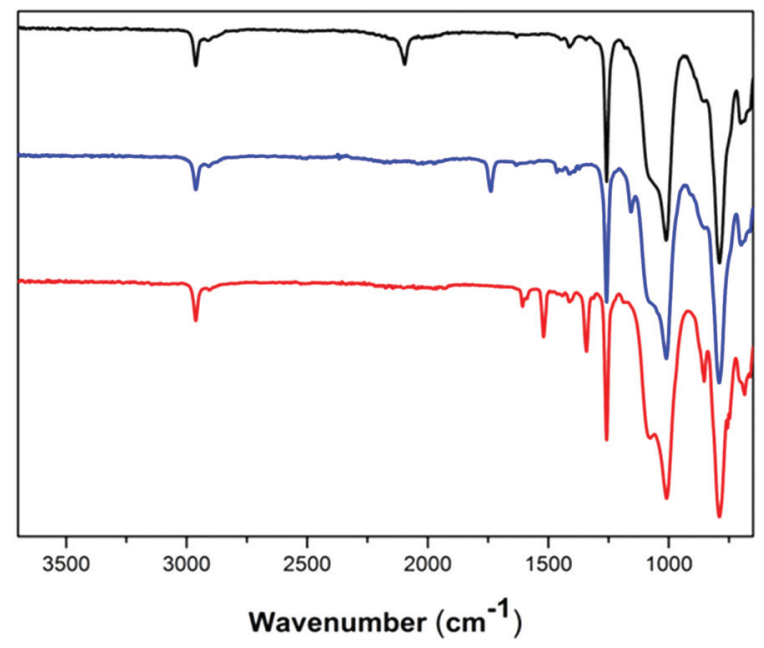

Fig. 3 FTIR spectra of azido-functional copolymer 3 (black, top), 2-bromoisobutyrate-functional copolymer 4 (blue, middle curve) and 4-nitrobenzene-functional copolymer 5 (red, bottom curve).

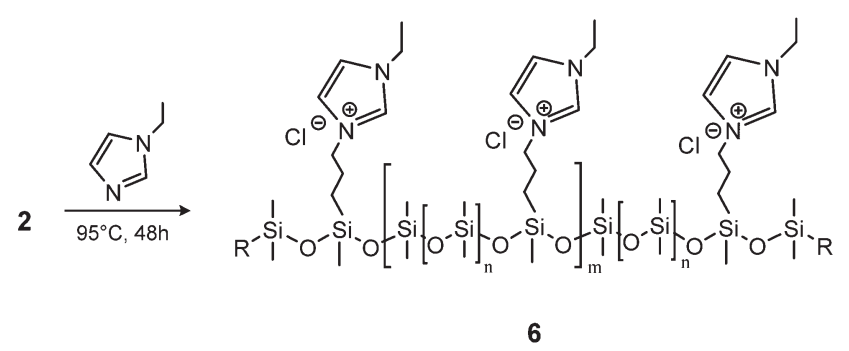

Scheme 4 Synthetic route to imidazole-functional copolymer.

Ionic polymers are a rapidly expanding class of materials with interesting and promising properties ${ }^{39-41}$ which have recently been extended to silicone materials. ${ }^{42}$ Thus, as an example of another possible post polymerisation modification, the prepared chloro-functional copolymer $\mathbf{2 a - 8}$ was used in a substitution reaction with 1-ethylimidazole to form the ionic copolymer seen in Scheme 4. This reaction was followed by ${ }^{1} \mathrm{H}-\mathrm{NMR}$ through a shift in the resonance of $\mathrm{CH}_{2}-\mathrm{Cl}\left(\delta_{\mathrm{H}}=\right.$ $3.50 \mathrm{ppm})$ to $\mathrm{CH}_{2}-\mathrm{N}^{+}\left(\delta_{\mathrm{H}}=4.43 \mathrm{ppm}\right)$. After the reaction, the orange-brown copolymer was less soluble in toluene, thereby demonstrating the increased ionic/polar nature of the copolymer 6. The SEC results for the chloro-functional copolymer 2a-8 and imidazolium-functional copolymer 6 can be seen in Table 1 and Fig. 4. As observed for the click-products, a slight shift towards the higher molecular region is seen in the SEC traces for copolymer $\mathbf{6}$, which indicates the successful attachment of the functional group.

The prepared chloro- and azido-functional siloxane copolymers have great potential in the preparation of functional silicone elastomers where the properties of the elastomers can be altered and improved according to the given application and the type of group attached to the copolymer. The specific functional groups could include many different types ${ }^{32}$ and are not limited to those used in this study. We are currently investi- 


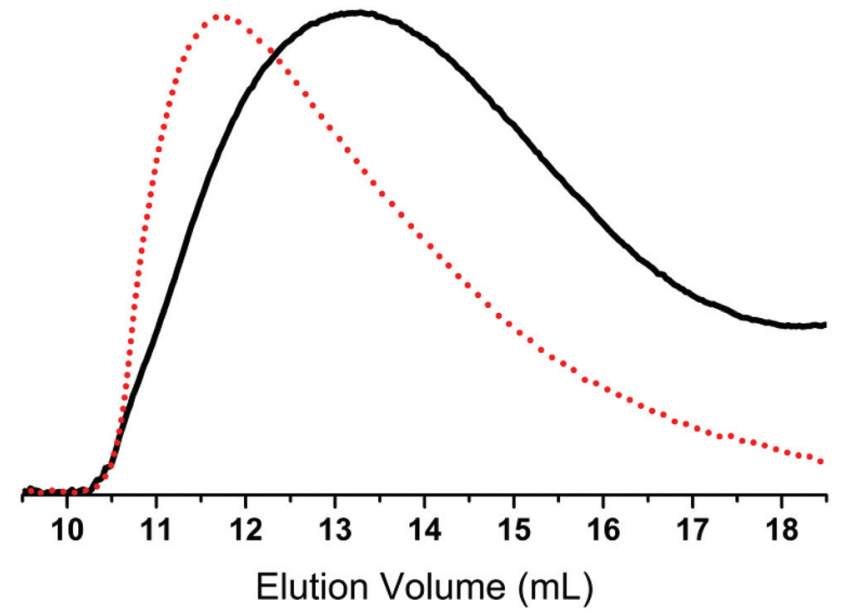

Fig. 4 An overlay of the RI SEC traces of chloro-functional copolymer 2a-8 (black, --) and imidazole-functional copolymer 6 (red, •.•).

gating the use of synthesised functional copolymers for the preparation of functional elastomers, thus elucidating their properties.

\section{Conclusions}

In conclusion, we have successfully synthesised telechelic vinyl/allyl chloro-, azido- and CuAAC-functionalised siloxane copolymers and ensured spatial control over the functional groups. The polycondensation reaction proved to be rapid and very robust, with high yields obtained. The method therefore offers a fast and reliable technique for the synthesis of structured functional polysiloxanes. The content of functional groups in the copolymers could be varied by changing the molecular weight of the hydride-terminated dimethylsiloxane pre-polymers used in the polycondensation reactions. Furthermore, the molecular weights of the copolymers could be tuned by varying the stoichiometry of the hydrosilane and methoxysilane starting materials. Polymers with any conceivable concentration of functionality and molecular weight can thereby be obtained.

\section{Acknowledgements}

The authors wish to acknowledge InnovationsFonden for its financial support.

\section{Notes and references}

1 R. K. Iha, K. L. Wooley, A. M. Nyström, D. J. Burke, M. J. Kade and C. J. Hawker, Chem. Rev., 2009, 109, 56205686.

2 J. de Jong, R. G. H. Lammertink and M. Wessling, Lab Chip, 2006, 6, 1125-1139.

3 M. A. Brook, Biomaterials, 2006, 27, 3274-3286.
4 C. Löwe, X. Zhang and G. Kovacs, Adv. Eng. Mater., 2005, 7, 361-367.

5 P. Brochu and Q. Pei, Macromol. Rapid Commun., 2010, 31, 10-36.

6 F. B. Madsen, A. E. Daugaard, S. Hvilsted, M. Y. Benslimane and A. L. Skov, Smart Mater. Struct., 2013, 22, 104002.

7 M. A. Brook, Silicon in organic, organometallic, and polymer chemistry, John Wiley \& Sons, New York, 2000.

8 S. Rubinsztajn and J. A. Cella, Macromolecules, 2005, 38, 1061-1063.

9 Y. Li and Y. Kawakami, Macromolecules, 1999, 32, 68716873.

10 Y. Li and Y. Kawakami, Macromolecules, 1999, 32, 87688773.

11 C. L. Homrighausen and T. M. Keller, J. Polym. Sci., Part A: Polym. Chem., 2002, 40, 1334-1341.

12 Y. Li, M. Seino and Y. Kawakami, Macromolecules, 2000, 33, 1-4.

13 R. Zhang, J. E. Mark and A. R. Pinhas, Macromolecules, 2000, 33, 3508-3510.

14 D. J. Parks and W. E. Piers, J. Am. Chem. Soc., 1996, 118, 9440-9441.

15 J. M. Blackwell, K. L. Foster, V. H. Beck and W. E. Piers, J. Org. Chem., 1999, 64, 4887-4892.

16 D. Parks, J. Blackwell and W. Piers, J. Org. Chem., 2000, 65, 3090-3098.

17 S. Rubinsztajn and J. A. Cella, Polym. Prepr., 2004, 45(1), 635-636.

18 J. Cella and S. Rubinsztajn, Macromolecules, 2008, 41, 6965-6971.

19 M. A. Brook, J. B. Grande and F. Ganachaud, Adv. Polym. Sci., 2011, 235, 161-183.

20 A. L. Larsen, K. Hansen, P. Sommer-Larsen, O. Hassager, A. Bach, S. Ndoni and M. Jørgensen, Macromolecules, 2003, 36, 10063-10070.

21 H. C. Kolb, M. G. Finn and K. B. Sharpless, Angew. Chem., Int. Ed., 2001, 40, 2004-2021.

22 P. Wu, A. K. Feldman, A. K. Nugent, C. J. Hawker, A. Scheel, B. Voit, J. Pyun, J. M. J. Fréchet, K. B. Sharpless and V. V. Fokin, Angew. Chem., Int. Ed., 2004, 43, 3928-3932.

23 M. Meldal, Macromol. Rapid Commun., 2008, 29, 10161051.

24 W. H. Binder and R. Sachsenhofer, Macromol. Rapid Commun., 2008, 29, 952-981.

25 A. D. Thomsen, E. Malmström and S. Hvilsted, J. Polym. Sci., Part A: Polym. Chem., 2006, 44, 6360-6377.

26 A. E. Daugaard, S. Hvilsted, T. S. Hansen and N. B. Larsen, Macromolecules, 2008, 41, 4321-4327.

27 S. Hvilsted, Polym. Int., 2012, 61, 485-494.

28 A. E. Daugaard and S. Hvilsted, Macromol. Rapid Commun., 2008, 29, 1119-1125.

29 F. Gonzaga, G. Yu and M. A. Brook, Macromolecules, 2009, 42, 9220-9224.

30 F. Gonzaga, G. Yu and M. A. Brook, Chem. Commun., 2009, 1730-1732. 
31 U. Schmidt, P. C. Zehetmaier and B. Rieger, Macromol. Rapid Commun., 2010, 31, 545-548.

32 F. B. Madsen, I. Dimitrov, A. E. Daugaard, S. Hvilsted and A. L. Skov, Polym. Chem., 2013, 4, 1700-1707.

33 T. Rambarran, F. Gonzaga and M. A. Brook, Macromolecules, 2012, 45, 2276-2285.

34 M. Rubin, T. Schwier and V. Gevorgyan, J. Org. Chem., 2002, 67, 1936-1940.

35 C. Xunjun, C. Yingde, Y. Guoqiang and L. Liewen, J. Appl. Polym. Sci., 2007, 106, 1007-1013.

36 P. J. Flory, Principles of Polymer Chemistry, Cornell University Press, Ithaca, New York, 1953, ch. 3, 8 and 9.

37 A. L. Larsen, P. Sommer-Larsen and O. Hassager, e-Polymers, 2004, 50, 1-18.
38 J. B. Grande, D. B. Thompson, F. Gonzaga and M. A. Brook, Chem. Commun., 2010, 46, 4988-4990.

39 M. D. Green, D. S. Cruz, Y. Ye, J. M. Layman, Y. A. Elabd, K. I. Winey and T. E. Long, Macromol. Chem. Phys., 2011, 212, 2522-2528.

40 P. Dimitrov-Raytchev, S. Beghdadi, A. Serghei and E. Drockenmuller, J. Polym. Sci., Part A: Polym. Chem., 2013, 51, 34-38.

41 S. Jana, V. A. Vasantha, L. P. Stubbs, A. Parthiban and J. G. Vancso, J. Polym. Sci., Part A: Polym. Chem., 2013, 51, 3260-3273.

42 L. Yu, L. B. Gonzalez, S. Hvilsted and A. L. Skov, Proc. SPIE-Int. Soc. Opt. Eng., 2014, 9056, 90560C. 